\title{
Regulation of glycolysis in head and neck squamous cell carcinoma
}

\author{
Dhruv Kumar, PhD \\ Department of Bioinformatics, SRM University, Sonepat, Haryana-131029, India
}

\begin{abstract}
Glycolysis is highly upregulated in head and neck squamous cell carcinoma (HNSCC). HNSCC glycolysis is an important contributor to disease progression and decreases sensitivity to radiation or chemotherapy. Despite therapeutic advances, the survival rates for HNSCC patients remain low. Understanding glycolysis regulation in HNSCC will facilitate the development of effective therapeutic strategies for this disease. In this review, we will evaluate the regulation of altered HNSCC glycolysis and possible therapeutic approaches by targeting glycolytic pathways.
\end{abstract}

\section{Keywords}

HNSCC; glycolysis; p53; HIF-1; GLUT-1; HK-II and LDH-A

\section{Background}

Head and neck squamous cell carcinoma (HNSCC) is the most common type of head and neck cancer [1-3]. HNSCC is the $6^{\text {th }}$ most common cancer worldwide with the incidence of 650,000 new cases every year [4]. It arises from the mucosal lining of the oral cavity, larynx, pharynx, oropharynx, hypopharynx, sinonasal tract and nasopharynx [1]. The major risk factors for HNSCC are tobacco and alcohol exposure [5-8], and human papilloma virus (HPV) infection [9-11]. These factors are associated with the HNSCC progression [7, 12].

Cancer cells are dependent of several metabolic processes including glycolysis [13], mitochondrial oxidative phosphorylation (OXPHOS) [14], and glutaminolysis to fulfil their energy requirements [15]. Like most aggressive tumors, HNSCC exhibit a high rate of glycolysis to meet their metabolic demands $[16,17]$. The outcome of the increased glycolysis in tumors can be visualized by $\left({ }^{18} \mathrm{~F}\right)$ fluoro-2-deoxy-D-glucose (FDG) positron emission tomography (PET)/computed tomography (CT) (FGD-PET/CT) using a glucose analog, FDG as a tracer [18-20]. The high FDG uptake by the HNSCC tumors potentially correlates with the glucose uptake by the cells. Moreover, the molecular imaging studies of HNSCC using FDG-PET/CT imaging demonstrated the high glucose uptake and increased glycolysis in HNSCC [21-23].

Corresponding Author: dhruvbhu@gmail.com,dhruv.k@ srmuniversity.ac.in.

Conflict of Interest

The author declares no competing interests. 
Glycolysis is a pathway that serves as the foundation for cellular metabolism [24, 25]. Glycolysis regulation in HNSCC is associated with the alteration in oncogenes, tumor suppressor genes, overexpression of glycolytic enzymes and glucose transporter. Under aerobic condition, cells produce only two adenosine triphosphates (ATPs) through glycolysis. Whereas, mitochondrial respiration can produces 36 ATPs by utilizing a product of glycolysis, pyruvate through OXPHOS. Under anaerobic conditions, pyruvate is reduced to lactate by an enzyme, lactate dehydrogenase A (LDH-A). Although, glycolysis generates less energy, ATP than OXPHOS, glycolysis is a major characteristic of cancer cell metabolism. Because of the weakened OXPHOS and less utilization of pyruvate, cancer cells produce less ATP through OXPHOS. In order to maintain a balance of energy, cancer cells aggressively perform glycolysis. The fast generation of energy during glycolysis promotes cell proliferation in rapidly growing cancer cells including HNSCC [13, 26, 27].

There are several steps involved in glycolysis to produce two molecules of pyruvate from one glucose molecule. Briefly, glucose first phosphorylates into glucose-6-phosphate by a catalytic enzyme, hexokinase. Next, glucose 6-phosphate converts into fructose 6-phosphate, fructose 6-phosphate converts into fructose 1,6-bisphosphate and finally it produces pyruvate as a end product of glycolysis [28]. In cancer cells, the elevated LDH-A catalyzes most of the pyruvates into lactate. The intracellular accumulation of lactate is extremely harmful as the abundance of lactate drastically lowers intracellular $\mathrm{pH}$. Consequently, the export of lactate by lactate transporters (Monocarboxylate transport proteins (MCTs)) into the extracellular space is extremely important for the cancer cells to main their intracellular $\mathrm{pH}$.

The purpose of this review is to highlight the current studies of HNSCC glycolysis and possible therapeutic interventions.

\section{Regulation of HNSCC glycolysis}

In 1927, Otto Warburg demonstrated that human tumor cells preferentially utilize glycolysis to generate energy using in vivo and in vitro models [29]. Warburg demonstrated that although mitochondrial respiration produces more ATP, tumors unlike normal cells, preferentially engage in glycolysis even in the presence of oxygen. Later, this phenomenon came to be known as the Warburg effect or aerobic glycolysis [30]. Increased aerobic glycolysis in cancer cells favorably accumulates lactic acid in tumor microenvironment. The accumulation of high amount of lactic acid tumor microenvironment is associated with metastatic spread and radioresistance in HNSCC [31, 32].

The underlying mechanisms involved in the preferential use of glycolysis by cancer cells include mitochondrial defects, adaptation to hypoxic tumor microenvironments, oncogenic signaling and abnormal expression of metabolic enzymes [33]. Several studies have demonstrated that altered glycolysis in HNSCC is associated with the activation of hypoxiainducible factor-1 (HIF-1), transketolase-like protein 1 (TKTL1), mutations in tumor suppressor gene, p53, as well as overexpression of the glucose transporters-1 (GLUT-1), and the glycolytic enzymes, Hexokinase-II (HK-II), lactate dehydrogenase A (LDH-A) and monocarboxylate transport proteins (MCTs) (Figure 1) [13, 34-38]. In the next section, we will discuss the role of each of these molecules in HNSCC pathogenesis. 


\section{Hypoxia-inducible factor-1}

Hypoxia-inducible factor-1 (HIF-1) is a transcription factor, which reprograms and regulates cancer cell metabolism including aerobic/anaerobic glycolysis and lactate production [39, 40]. HIF-1 is a heterodimer consisting of a highly regulated HIF-1a subunit and a constitutively expressed HIF-1 $\beta$ subunit [41-43]. A high level of HIF-1a protein is common in many types of solid tumors including head and neck [44-47]. Recently, it has been reported that HIF-1a complex binds hypoxia response elements in the promoter region of target genes, which include enzymes involved in glycolysis and $\mathrm{pH}$ regulation, such as phosphoglycerate kinase [48], carbonic anhydrase CA9 [49], hexokinase [50], lactate dehydrogenase [51] and glucose transporters, GLUT-1 and GLUT-3 [41, 52-54].

HIF-1 increases the rate of glucose uptake in cancer cells through the induction of glucose transporters and further induces glucose phosphorylation by increasing HK-II activity [50]. HIF-1 can regulate complete glycolysis pathway by increasing the amounts of the enzymes (e.g. HK-II, LDH-A and phospho fructokinase1 (PFK1)) involved in this process [55]. Seagroves et al. (2001) reported that most of the enzymes necessary for glycolysis in mammalian cells are regulated by HIF-1 [56]. Moreover, the overexpression of HIF-1 promotes the expression of glycolytic enzymes, which favors the use of glucose in glycolysis and lactate export into extracellular space.

\section{Transketolase-like protein 1}

Transketolase-like protein 1 (TKTL1) is a heterodimer protein belonging to the transketolase family [57]. The overexpression of TKTL1 is associated with the cell growth, glucose consumption and lactate production in many cancer cells and is considered as a potential proto-oncogene [58-61]. In 2009, Smith and coworkers reported that the TKTL1 induced aerobic glycolytic phenotype in head and neck and lung cancer by increasing fructose-6phosphate and glyceraldehyde-3-phosphate [61]. Moreover, the overexpression of TKTL1 is strongly correlated with tumor progression in colorectal cancer [62]. The function of TKTL1 is not very well understood in HNSCC. Recently, Grimm et al. (2014) demonstrated that the overexpression of TKTL1 is negatively correlated with the survival of patients with OSCC [63]. In 2010, Sun et al. reported the overexpression of TKTL1 in HNSCC tumors compared to normal mucosa [64]. Moreover, the overexpression of TKTL1 in HNSCC cells promoted cellular proliferation in vitro and tumor growth in vivo [64]. The overexpression of TKTL1 increased the production of fructose-6-phosphate and glyceraldehyde-3-phosphate, and further increased lactate production by stabilizing HIF1a (Figure 1) [64].

p53

$p 53$ is a tumor suppressor gene, which is highly mutated in human cancers [65]. The $p 53$ signaling pathway is activated in response to a variety of stress signals, allowing $p 53$ to coordinate transcription programs that ultimately contribute to tumor suppression [66]. p53 also regulates cellular metabolism by regulating glycolysis and OXPHOS steps via transcriptional regulation of its downstream genes TP53-induced glycolysis regulator (TIGAR) [67]. Loss or gain of function, through mutations in p53 (Mut-p53) is a common 
feature in the majority of human cancers $[68,69]$. Recently, it has been reported that the gain-of-function in $p 53$ mediates metabolic changes in tumors and promotes tumor growth [70]. Zhang et al. (2013) demonstrated that Mut-p53, gain of function promoted glycolysis and Warburg effect in several cancers by increasing GLUT-1 expression through activating RhoA/ROCK signaling pathway in both in vitro and in vivo models [71]. Moreover, the Mut-p53 was reported to induce the expression of glycolytic enzyme, HK-II, which promoted glycolysis in rats [72]. Although, mutations in $p 53$ is a key factor in the regulation of cancer cell metabolism, the inactivation of $p 53$ in HPV positive HNSCC indicates an alternative mechanisms of HNSCC metabolic regulation [73-75]. Currently, the roles of Mut-p53 in regulation of tumor metabolism remain unclear. Whereas, some studies have demonstrated that glycolytic inhibition potentiates radiation toxicity in Mut-p53, but not in WT-p53 expressing HNSCC cells [68, 76].

\section{Glucose transporter-1}

Glucose transporter-1 (GLUT-1) encoded by a gene called SLC2A1, which mediates the cellular uptake of glucose into many tissues, and maintains glucose concentration in blood [77-79]. Overexpression of GLUT-1 was reported in several cancers including head and neck [80-82]. In 2008, Li et al. reported the overexpression of GLUT-1 in primary and recurrent HNSCC tumors with the high accumulation of FDG [83], which correlates with the high glucose uptake and poor patients survival. These findings indicate that the overexpression of GLUT-1 in HNSCC is associated with glucose uptake.

\section{Hexokinase-II}

Hexokinase-II (HK-II) is a glycolytic enzyme, which phosphorylates glucose into glucose-6phosphate in many tissues including muscle and adipose [84, 85]. HK-II is one of the ratelimiting enzymes of glycolysis [13], which is highly upregulated in many cancers including HNSCC [63, 86-88]. Recently, Chen et al. (2014) reported the overexpression of HK-II in laryngeal squamous cell carcinoma (LSCC) cells and the effect of HK-II expression in tumor progression. HK-II knocked down by HK-II shRNA in laryngeal cell carcinoma, Hep-2, decreased cell viability and increased apoptosis by arresting G0-G1 phase of cell cycle. Moreover, the depletion of HK-II resulted in reduced xenograft tumor [89]. These findings suggest that the HK-II expression in HNSCC plays an important role in the tumor progression by upregulating tumor glycolysis.

\section{Lactate dehydrogenase $\mathrm{A}$}

The lactate dehydrogenase A (LDH-A) is an enzyme, which is highly upregulated in cancer cells. LDH-A catalyzes the last step of anaerobic glycolysis, converts pyruvate into lactate during glycolysis [90, 91]. There are five active LDH isoenzymes in human tissue, each of which is a tetrametric metabolic enzyme composed of two major subunits, A and B, encoded by $L d h-A$ and $L d h-B$ genes, respectively. When there are more A chains than B chains, the LDH isoenzymes become more efficient in catalyzing the conversion of pyruvate into lactate; conversely, an excess of B chains favors the conversion of pyruvate into acetyl-CoA. The dependence of tumor cells on LDH-A has been demonstrated in many cancer types 
including OSCC [63, 92]. During the conversion of pyruvate into lactate, nicotinamide adenine dinucleotide (NADH) reduced to $\mathrm{NAD}^{+}$ion, which required to drive glycolysis in cancer cells. LDH-A is a key enzyme involved in the Warburg effect and in sustaining cancer's glycolytic phenotype [93]. Recently, Blatt et al., (2016) demonstrated that the high lactate levels in HNSCC tumors are significantly negatively correlated with patient survival [94].

\section{Monocarboxylate transports}

Most solid tumors are highly glycolytic, which produce significant amount of lactic acid in extracellular environment, contributing to the acidic tumor microenvironment [95]. In this condition, monocarboxylate transports (MCTs) play an important role in the maintenance of the lactate shuttle, and $\mathrm{pH}$ regulation in highly glycolytic solid tumors [96]. MCTs are transmembrane proteins that facilitate the transport of variety of substrates such as pyruvate and lactate [97]. The overexpression of monocarboxylate transports (MCT1 and MCT4) have been reported in several cancers including head and neck cancer and is associated with the poor prognosis [27, 96, 98-100]. The regulation of MCT1 and MCT4 depends on the specific cell types and their function [101]. Several studies have demonstrated that MCT1 works as a lactate bidirectional transporter, whereas MCT4 only effluxes lactate from the cells $[102,103]$. In solid tumors, cancer cells could also import lactate through MCT1 from the most glycolytic tumor cells $[103,104]$ or tumor-associated fibroblasts to fuel mitochondrial respiration and thereby spare glucose for hypoxic tumor cells [105, 106]. In 2011, Boidot et al. demonstrated that loss of p53 in hypoxia condition induces MCT1 expression and increases lactate shuttle in elevated glycolytic tumors [107]. As discussed above, the intracellular accumulation of lactate is tremendously harmful for the cancer cells in highly glycolytic solid tumor. Thus, the export of lactate into the extracellular space through MCTs is extremely necessary for the survival of cancer cells. Therefore, targeting MCTs in highly glycolytic HNSCC tumors could be a potential therapeutic approach to control tumor growth $[95,108,109]$.

\section{Therapeutic approaches for HNSCC by targeting glycolytic pathways}

Despite development of several metabolic inhibitors, not many studies have been reported to target glycolytic pathway in HNSCC. As HK-II phosphorylates glucose to glucose-6phosphate, most of the glycolysis inhibitors were designed to target HK-II. lonidamine, 2deoxy-D-glucose (2-DG) and 3-bromopyruvate (3-BP) are the most commonly tested HK-II inhibitors being used in both pre-clinical and clinical model either alone or in combination with chemotherapy and radiation therapy [33, 110-114]. Simons et al., (2007) demonstrated that 2-DG potentiates cisplatin cytotoxicity in HNSCC xenografts model $[111,112]$. In cancer cells, glucose deprivation as well as treatment with 2-DG has been shown to induce oxidative stress and sensitivity to radiation and chemotherapy [115-118]. In 2008, Ihrlund et al. demonstrated that 3-BP enhanced cisplatin cytotoxicity in pre-clinical setting [119]. Other clinical studies demonstrated that the combination of lonidamine to either radiation therapy or chemotherapy improved clinical outcomes in HNSCC patients [120,121]. 
As GLUT-1 increases glucose uptake in HNSCC and potentiates glycolysis, it is important to target GLUT-1 to inhibit glycolysis. Most recently, Wang et al. (2013) demonstrated that the inhibition of GLUT-1 activity and expression can sensitize HNSCC cells to cisplatin treatment in both in vitro and in vivo models. They demonstrated that glucose uptake was reduced in HNSCC cells by knocking down GLUT-1 with shRNA or blocking GLUT-1 by anti-GLUT-1 antibody. Both anti-GLUT-1 antibody and GLUT-1-shRNA sensitized HNSCC cells to cisplatin treatment under both normoxia and hypoxia conditions [122]. Another study by Li et al. (2013) demonstrated that the inhibition of GLUT-1 in HNSCC significantly inhibited cell viability and colony formation. Further, GLUT-1 inhibition reduced tumor growth in xenograft model [123]. In addition to HK-II and GLUT-1, HIF-1a, p53, TKTL1, LDH-A and MCTs can also be targeted to inhibit glycolytic pathway in HNSCC.

\section{Conclusion}

In this review, we discussed the role of HIF-1, TKTL1, p53, GLUT-1, HK-II, LDH-A and MCTs in HNSCC metabolism. In general, expression of these factors was associated with poor survival, and resistance to radiation and chemotherapeutic agents in HNSCC. The effect of these markers in HNSCC glycolysis is not very well investigated. Therefore, the detailed study and evaluation of these factors in HNSCC glycolysis may provide clues for the best treatment option for HNSCC patients with radio or chemo resistance.

\section{Acknowledgments}

This work was partially supported by National Institute of General Medical Sciences, National Institute of Health (P20 GM103418) funded KINBRE postdoc fellowship.

\section{References}

1. Sanderson RJ, Ironside JA. Squamous cell carcinomas of the head and neck. BMJ. 2002; 325(7368): 822-7. https://doi.org/10.1136/bmj.325.7368.822. [PubMed: 12376446]

2. Abgral R, et al. Does 18F-FDG PET/CT improve the detection of posttreatment recurrence of head and neck squamous cell carcinoma in patients negative for disease on clinical follow-up? J Nucl Med. 2009; 50(1):24-9. https://doi.org/10.2967/jnumed.108.055806. [PubMed: 19091901]

3. Daley T, Darling M. Nonsquamous cell malignant tumours of the oral cavity: an overview. J Can Dent Assoc. 2003; 69(9):577-82. [PubMed: 14653933]

4. Jemal A, et al. Global cancer statistics. CA Cancer J Clin. 2011; 61(2):69-90. https://doi.org/ 10.3322/caac.20107. [PubMed: 21296855]

5. Padmavathy G, Reddy DJ. Aetiological factors of carcinoma of the mouth and pharynx in Guntur. J Indian Med Assoc. 1960; 34:84-8. [PubMed: 14429713]

6. Wynder EL, Bross IJ. Aetiological factors in mouth cancer; an approach to its prevention. Br Med J. 1957; 1(5028):1137-43. https://doi.org/10.1136/bmj.1.5028.1137. [PubMed: 13426561]

7. Brennan JA, et al. Association between Cigarette-Smoking and Mutation of the P53 Gene in Squamous-Cell Carcinoma of the Head and Neck. New England Journal of Medicine. 1995; 332(11):712-717. https://doi.org/10.1056/NEJM199503163321104. [PubMed: 7854378]

8. Franceschi S, et al. Comparison of the effect of smoking and alcohol drinking between oral and pharyngeal cancer. International Journal of Cancer. 1999; 83(1):1-4. https://doi.org/10.1002/ (SICI)1097-0215(19990924)83:1<1::AID-IJC1>3.0.CO;2-8https://doi.org/10.1002/ (SICI)1097-0215(19990924)83:1<1::AID-IJC1>3.3.CO;2-\#. [PubMed: 10449598] 
9. Chaturvedi AK, et al. Human papillomavirus and rising oropharyngeal cancer incidence in the United States. J Clin Oncol. 2011; 29(32):4294-301. https://doi.org/10.1200/JCO.2011.36.4596. [PubMed: 21969503]

10. Ragin CC, Modugno F, Gollin SM. The epidemiology and risk factors of head and neck cancer: a focus on human papillomavirus. J Dent Res. 2007; 86(2):104-14. https://doi.org/ 10.1177/154405910708600202. [PubMed: 17251508]

11. Wierzbicka M, et al. The rationale for HPV-related oropharyngeal cancer de-escalation treatment strategies. Contemp Oncol (Pozn). 2015; 19(4):313-22. https://doi.org/10.5114/wo.2015.54389. [PubMed: 26557780]

12. Friemel J, et al. Pretreatment oral hygiene habits and survival of head and neck squamous cell carcinoma (HNSCC) patients. BMC Oral Health. 2016; 16(1):33. https://doi.org/10.1186/ s12903-016-0185-0. [PubMed: 26969620]

13. Hamanaka RB, Chandel NS. Targeting glucose metabolism for cancer therapy. J Exp Med. 2012; 209(2):211-5. https://doi.org/10.1084/jem.20120162. [PubMed: 22330683]

14. Frezza C, Gottlieb E. Mitochondria in cancer: Not just innocent bystanders. Seminars in Cancer Biology. 2009; 19(1):4-11. https://doi.org/10.1016/j.semcancer.2008.11.008. [PubMed: 19101633]

15. Alfarouk KO, et al. Evolution of Tumor Metabolism might Reflect Carcinogenesis as a Reverse Evolution process (Dismantling of Multicellularity). Cancers (Basel). 2011; 3(3):3002-17. https:// doi.org/10.3390/cancers3033002. [PubMed: 24310356]

16. Richtsmeier WJ, Dauchy R, Sauer LA. In vivo nutrient uptake by head and neck cancers. Cancer Res. 1987; 47(19):5230-3. [PubMed: 3621209]

17. Sandulache VC, et al. Glucose, not glutamine, is the dominant energy source required for proliferation and survival of head and neck squamous carcinoma cells. Cancer. 2011; 117(13): 2926-38. https://doi.org/10.1002/cncr.25868. [PubMed: 21692052]

18. Han M, et al. The Correlations Between MRI Perfusion, Diffusion Parameters, and F-18-FDG PET Metabolic Parameters in Primary Head-and-Neck Cancer A Cross-Sectional Analysis in Single Institute. Medicine. 2015; 94(47) https://doi.org/10.1097/MD.0000000000002141.

19. Abgral R, et al. Prognostic evaluation of percentage variation of metabolic tumor burden calculated by dual-phase FDG PET-CT imaging in patients with head and neck cancer. Head Neck. 2015

20. Robin P, et al. Diagnostic performance of FDG PET/CT to detect subclinical HNSCC recurrence 6 months after the end of treatment. Eur J Nucl Med Mol Imaging. 2015; 42(1):72-8. https://doi.org/ 10.1007/s00259-014-2889-1. [PubMed: 25169701]

21. Paidpally V, et al. FDG-PET/CT imaging biomarkers in head and neck squamous cell carcinoma. Imaging Med. 2012; 4(6):633-647. https://doi.org/10.2217/iim.12.60. [PubMed: 23482696]

22. Huebbers CU, et al. High glucose uptake unexpectedly is accompanied by high levels of the mitochondrial beta-F1-ATPase subunit in head and neck squamous cell carcinoma. Oncotarget. 2015; 6(34):36172-36184. [PubMed: 26452026]

23. Klement RJ. Restricting carbohydrates to fight head and neck cancer-is this realistic? Cancer Biol Med. 2014; 11(3):145-61. [PubMed: 25364576]

24. Lane AN, Fan TWM, Higashi RM. Metabolic acidosis and the importance of balanced equations. Metabolomics. 2009; 5(2):163-165. https://doi.org/10.1007/s11306-008-0142-2.

25. Pramanik J, Keasling JD. Stoichiometric model of Escherichia coli metabolism: Incorporation of growth-rate dependent biomass composition and mechanistic energy requirements. Biotechnology and Bioengineering. 1997; 56(4):398-421. https://doi.org/10.1002/ (SICI)1097-0290(19971120)56:4<398::AID-BIT6>3.3.CO;2-Fhttps://doi.org/10.1002/ (SICI)1097-0290(19971120)56:4<398::AID-BIT6>3.0.CO;2-J. [PubMed: 18642243]

26. Pfeiffer T, Schuster S, Bonhoeffer S. Cooperation and competition in the evolution of ATPproducing pathways. Science. 2001; 292(5516):504-7. https://doi.org/10.1126/science.1058079. [PubMed: 11283355]

27. Curry JM, et al. Cancer metabolism, stemness and tumor recurrence: MCT1 and MCT4 are functional biomarkers of metabolic symbiosis in head and neck cancer. Cell Cycle. 2013; 12(9): 1371-84. https://doi.org/10.4161/cc.24092. [PubMed: 23574725] 
28. Kresge N, Simoni RD, Hill RL. JBC Centennial - 1905-2005 - 100 years of biochemistry and molecular biology - Otto Fritz Meyerhof and the elucidation of the glycolytic pathway. Journal of Biological Chemistry. 2005; 280(4)

29. Warburg O, Wind F, Negelein E. The Metabolism of Tumors in the Body. J Gen Physiol. 1927; 8(6):519-30. https://doi.org/10.1085/jgp.8.6.519. [PubMed: 19872213]

30. Warburg O. On the origin of cancer cells. Science. 1956; 123(3191):309-14. https://doi.org/ 10.1126/science.123.3191.309. [PubMed: 13298683]

31. Sattler UGA, et al. Glycolytic metabolism and tumour response to fractionated irradiation. Radiotherapy and Oncology. 2010; 94(1):102-109. https://doi.org/10.1016/j.radonc.2009.11.007. [PubMed: 20036432]

32. Quennet V, et al. Tumor lactate content predicts for response to fractionated irradiation of human squamous cell carcinomas in nude mice. Radiotherapy and Oncology. 2006; 81(2):130-135. https://doi.org/10.1016/j.radonc.2006.08.012. [PubMed: 16973228]

33. Pelicano H, et al. Glycolysis inhibition for anticancer treatment. Oncogene. 2006; 25(34):4633-46. https://doi.org/10.1038/sj.onc.1209597. [PubMed: 16892078]

34. Vander, Heiden MG., Cantley, LC., Thompson, CB. Understanding the Warburg effect: the metabolic requirements of cell proliferation. Science. 2009; 324(5930):1029-33. https://doi.org/ 10.1126/science.1160809. [PubMed: 19460998]

35. Zhang M, et al. Oral cancer cells may rewire alternative metabolic pathways to survive from siRNA silencing of metabolic enzymes. Bmc Cancer. 2014; 14 https://doi.org/ 10.1186/1471-2407-14-223.

36. Bensaad K, et al. TIGAR, a p53-inducible regulator of glycolysis and apoptosis. Cell. 2006; 126(1):107-20. https://doi.org/10.1016/j.cell.2006.05.036. [PubMed: 16839880]

37. Dang CV, et al. Hypoxia and metabolism - Opinion - The interplay between MYC and HIF in cancer. Nature Reviews Cancer. 2008; 8(1):51-56. https://doi.org/10.1038/nrc2274. [PubMed: 18046334]

38. Elstrom RL, et al. Akt stimulates aerobic glycolysis in cancer cells. Cancer Research. 2004; 64(11):3892-3899. https://doi.org/10.1158/0008-5472.CAN-03-2904. [PubMed: 15172999]

39. Semenza GL. HIF-1: upstream and downstream of cancer metabolism. Curr Opin Genet Dev. 2010; 20(1):51-6. https://doi.org/10.1016/j.gde.2009.10.009. [PubMed: 19942427]

40. Denko NC. Hypoxia, HIF1 and glucose metabolism in the solid tumour. Nat Rev Cancer. 2008; 8(9):705-13. https://doi.org/10.1038/nrc2468. [PubMed: 19143055]

41. Maxwell PH, Pugh CW, Ratcliffe PJ. Inducible operation of the erythropoietin $3^{\prime}$ enhancer in multiple cell lines: evidence for a widespread oxygen-sensing mechanism. Proc Natl Acad Sci U S A. 1993; 90(6):2423-7. https://doi.org/10.1073/pnas.90.6.2423. [PubMed: 8460154]

42. Firth JD, et al. Oxygen-regulated control elements in the phosphoglycerate kinase 1 and lactate dehydrogenase A genes: similarities with the erythropoietin $3^{\prime}$ enhancer. Proc Natl Acad Sci U S A. 1994; 91(14):6496-500. https://doi.org/10.1073/pnas.91.14.6496. [PubMed: 8022811]

43. Semenza GL, et al. Transcriptional regulation of genes encoding glycolytic enzymes by hypoxiainducible factor 1. J Biol Chem. 1994; 269(38):23757-63. [PubMed: 8089148]

44. Semenza GL. Hypoxia, clonal selection, and the role of HIF-1 in tumor progression. Crit Rev Biochem Mol Biol. 2000; 35(2):71-103. https://doi.org/10.1080/10409230091169186. [PubMed: 10821478]

45. Semenza GL. Involvement of hypoxia-inducible factor 1 in human cancer. Intern Med. 2002; 41(2):79-83. https://doi.org/10.2169/internalmedicine.41.79. [PubMed: 11868612]

46. Semenza GL. Defining the role of hypoxia-inducible factor 1 in cancer biology and therapeutics. Oncogene. 2010; 29(5):625-34. https://doi.org/10.1038/onc.2009.441. [PubMed: 19946328]

47. Swartz JE, et al. Clinical implications of hypoxia biomarker expression in head and neck squamous cell carcinoma: a systematic review. Cancer Medicine. 2015; 4(7):1101-1116. https://doi.org/ 10.1002/cam4.460. [PubMed: 25919147]

48. Semenza GL, et al. Transcriptional Regulation of Genes Encoding Glycolytic-Enzymes by Hypoxia-Inducible Factor-1. Journal of Biological Chemistry. 1994; 269(38):23757-23763. [PubMed: 8089148] 
49. Wykoff CC, et al. Hypoxia-inducible expression of tumor-associated carbonic anhydrases. Cancer Research. 2000; 60(24):7075-7083. [PubMed: 11156414]

50. Mathupala SP, Rempel A, Pedersen PL. Glucose catabolism in cancer cells: identification and characterization of a marked activation response of the type II hexokinase gene to hypoxic conditions. J Biol Chem. 2001; 276(46):43407-12. https://doi.org/10.1074/jbc.M108181200. [PubMed: 11557773]

51. Firth JD, Ebert BL, Ratcliffe PJ. Hypoxic Regulation of Lactate-Dehydrogenase-a- Interaction between Hypoxia-Inducible Factor-1 and Camp Response Elements. Journal of Biological Chemistry. 1995; 270(36):21021-21027. https://doi.org/10.1074/jbc.270.36.21021. [PubMed: 7673128]

52. Ebert BL, Firth JD, Ratcliffe PJ. Hypoxia and Mitochondrial Inhibitors Regulate Expression of Glucose Transporter-1 Via Distinct Cis-Acting Sequences. Journal of Biological Chemistry. 1995; 270(49):29083-29089. https://doi.org/10.1074/jbc.270.49.29083. [PubMed: 7493931]

53. Maxwell PH, et al. Hypoxia-inducible factor-1 modulates gene expression in solid tumors and influences both angiogenesis and tumor growth. Proceedings of the National Academy of Sciences of the United States of America. 1997; 94(15):8104-8109. https://doi.org/10.1073/pnas. 94.15.8104. [PubMed: 9223322]

54. Gronroos, TJ., et al. Hypoxia, blood flow and metabolism in squamous-cell carcinoma of the head and neck: correlations between multiple immunohistochemical parameters and PET; Bmc Cancer. 2014. p. 14https://doi.org/10.1186/1471-2407-14-876

55. Minchenko O, Opentanova I, Caro J. Hypoxic regulation of the 6-phosphofructo-2-kinase/ fructose-2,6-bisphosphatase gene family (PFKFB-1-4) expression in vivo. Febs Letters. 2003; 554(3):264-270. https://doi.org/10.1016/S0014-5793(03)01179-7. [PubMed: 14623077]

56. Seagroves TN, et al. Transcription factor HIF-1 is a necessary mediator of the pasteur effect in mammalian cells. Molecular and Cellular Biology. 2001; 21(10):3436-3444. https://doi.org/ 10.1128/MCB.21.10.3436-3444.2001. [PubMed: 11313469]

57. Coy JF, et al. Molecular cloning of tissue-specific transcripts of a transketolase-related gene: Implications for the evolution of new vertebrate genes. Genomics. 1996; 32(3):309-316. https:// doi.org/10.1006/geno.1996.0124. [PubMed: 8838793]

58. Xu XJ, et al. Transketolase-like protein 1 (TKTL1) is required for rapid cell growth and full viability of human tumor cells. International Journal of Cancer. 2009; 124(6):1330-1337. https:// doi.org/10.1002/ijc.24078. [PubMed: 19065656]

59. Staiger WI, et al. Expression of the mutated transketolase TKTL1, a molecular marker in gastric cancer. Oncology Reports. 2006; 16(4):657-661. https://doi.org/10.3892/or.16.4.657. [PubMed: 16969476]

60. Langbein S, et al. Expression of transketolase TKTL1 predicts colon and urothelial cancer patient survival: Warburg effect reinterpreted. British Journal of Cancer. 2006; 94(4):578-585. https:// doi.org/10.1038/sj.bjc.6602962. [PubMed: 16465194]

61. Smith IM, et al. Coordinated Activation of Candidate Proto-Oncogenes and Cancer Testes Antigens via Promoter Demethylation in Head and Neck Cancer and Lung Cancer. Plos One. 2009; 4(3) https://doi.org/10.1371/journal.pone.0004961.

62. Diaz-Moralli S, et al. Transketolase-Like 1 Expression Is Modulated during Colorectal Cancer Progression and Metastasis Formation. Plos One. 2011; 6(9) https://doi.org/10.1371/journal.pone. 0025323.

63. Grimm M, et al. Association of cancer metabolism-related proteins with oral carcinogenesis indications for chemoprevention and metabolic sensitizing of oral squamous cell carcinoma? J Transl Med. 2014; 12:208. https://doi.org/10.1186/1479-5876-12-208. [PubMed: 25048361]

64. Sun W, et al. TKTL1 is activated by promoter hypomethylation and contributes to head and neck squamous cell carcinoma carcinogenesis through increased aerobic glycolysis and HIF1alpha stabilization. Clin Cancer Res. 2010; 16(3):857-66. https://doi.org/ 10.1158/1078-0432.CCR-09-2604. [PubMed: 20103683]

65. Vogelstein B, Lane D, Levine AJ. Surfing the p53 network. Nature. 2000; 408(6810):307-310. https://doi.org/10.1038/35042675. [PubMed: 11099028] 
66. Vousden KH, Prives C. Blinded by the Light: The Growing Complexity of p53. Cell. 2009; 137(3): 413-31. https://doi.org/10.1016/j.cell.2009.04.037. [PubMed: 19410540]

67. Wanka C, Steinbach JP, Rieger J. Tp53-induced Glycolysis and Apoptosis Regulator (TIGAR) Protects Glioma Cells from Starvation-induced Cell Death by Up-regulating Respiration and Improving Cellular Redox Homeostasis. Journal of Biological Chemistry. 2012; 287(40):3343633446. https://doi.org/10.1074/jbc.M112.384578. [PubMed: 22887998]

68. Muller PA, Vousden KH. p53 mutations in cancer. Nat Cell Biol. 2013; 15(1):2-8. https://doi.org/ 10.1038/ncb2641. [PubMed: 23263379]

69. Rivlin N, et al. Mutations in the p53 Tumor Suppressor Gene: Important Milestones at the Various Steps of Tumorigenesis. Genes Cancer. 2011; 2(4):466-74. https://doi.org/ 10.1177/1947601911408889. [PubMed: 21779514]

70. Liu J, et al. Tumor suppressor p53 and its mutants in cancer metabolism. Cancer Letters. 2015; 356(2):197-203. https://doi.org/10.1016/j.canlet.2013.12.025. [PubMed: 24374014]

71. Zhang, C., et al. Tumour-associated mutant p53 drives the Warburg effect; Nature Communications. 2013. p. 4https://doi.org/10.1038/ncomms3935

72. Goel A, Mathupala SP, Pedersen PL. Glucose metabolism in cancer - Evidence that demethylation events play a role in activating type II hexokinase gene expression. Journal of Biological Chemistry. 2003; 278(17):15333-15340. https://doi.org/10.1074/jbc.M300608200. [PubMed: 12566445]

73. van, Monsjou HS., et al. Human papillomavirus status in young patients with head and neck squamous cell carcinoma. International Journal of Cancer. 2012; 130(8):1806-1812. https:// doi.org/10.1002/ijc.26195. [PubMed: 21607949]

74. Fakhry C, Gillison ML. Clinical implications of human papillomavirus in head and neck cancers. Journal of Clinical Oncology. 2006; 24(17):2606-2611. https://doi.org/10.1200/JCO. 2006.06.1291. [PubMed: 16763272]

75. Munger K, Howley PM. Human papillomavirus immortalization and transformation functions. Virus Research. 2002; 89(2):213-228. https://doi.org/10.1016/S0168-1702(02)00190-9. [PubMed: 12445661]

76. Petitjean A, et al. Impact of mutant p53 functional properties on TP53 mutation patterns and tumor phenotype: lessons from recent developments in the IARC TP53 database. Hum Mutat. 2007; 28(6):622-9. https://doi.org/10.1002/humu.20495. [PubMed: 17311302]

77. Mueckler M, et al. Sequence and structure of a human glucose transporter. Science. 1985; 229(4717):941-5. https://doi.org/10.1126/science.3839598. [PubMed: 3839598]

78. Thorens B, Mueckler M. Glucose transporters in the 21st Century. Am J Physiol Endocrinol Metab. 2010; 298(2):E141-5. https://doi.org/10.1152/ajpendo.00712.2009. [PubMed: 20009031]

79. Kasahara M, Hinkle PC. Reconstitution and purification of the D-glucose transporter from human erythrocytes. J Biol Chem. 1977; 252(20):7384-90. [PubMed: 903365]

80. Mellanen P, et al. Expression of Glucose Transporters in Head-and-Neck Tumors. International Journal of Cancer. 1994; 56(5):622-629. https://doi.org/10.1002/ijc.2910560503. [PubMed: 8314336]

81. Marom EM, et al. Correlation of FDG-PET imaging with Glut-1 and Glut-3 expression in earlystage non-small cell lung cancer. Lung Cancer. 2001; 33(2-3):99-107. https://doi.org/10.1016/ S0169-5002(00)00250-6. [PubMed: 11551404]

82. Higashi T, et al. Expression of glucose transporters in human pancreatic tumors compared with increased FDG accumulation in PET study. Journal of Nuclear Medicine. 1997; 38(9):1337-1344. [PubMed: 9293783]

83. Li SJ, et al. Expression of Glut-1 in primary and recurrent head and neck squamous cell carcinomas, and compared with 2-[18F]fluoro-2-deoxy-D-glucose accumulation in positron emission tomography. Br J Oral Maxillofac Surg. 2008; 46(3):180-6. https://doi.org/10.1016/ j.bjoms.2007.11.003. [PubMed: 18093707]

84. Osawa H, et al. Regulation of hexokinase II gene transcription and glucose phosphorylation by catecholamines, cyclic AMP, and insulin. Diabetes. 1995; 44(12):1426-32. https://doi.org/10.2337/ diabetes.44.12.1426https://doi.org/10.2337/diab.44.12.1426. [PubMed: 7589850] 
85. Roberts DJ, Miyamoto S. Hexokinase II integrates energy metabolism and cellular protection: Akting on mitochondria and TORCing to autophagy. Cell Death Differ. 2015; 22(2):364. https:// doi.org/10.1038/cdd.2014.173https://doi.org/10.1038/cdd.2014.208. [PubMed: 25578149]

86. Patra KC, et al. Hexokinase 2 Is Required for Tumor Initiation and Maintenance and Its Systemic Deletion Is Therapeutic in Mouse Models of Cancer (vol 24, pg 213, 2013). Cancer Cell. 2013; 24(3):399-399. https://doi.org/10.1016/j.ccr.2013.08.029.

87. Mathupala SP, Ko YH, Pedersen PL. Hexokinase-2 bound to mitochondria: Cancer's stygian link to the "Warburg effect" and a pivotal target for effective therapy. Seminars in Cancer Biology. 2009; 19(1):17-24. https://doi.org/10.1016/j.semcancer.2008.11.006. [PubMed: 19101634]

88. Yamada T, et al. Correlation of metabolism/hypoxia markers and fluorodeoxyglucose uptake in oral squamous cell carcinomas. Oral Surgery Oral Medicine Oral Pathology Oral Radiology. 2012; 113(4):464-471. https://doi.org/10.1016/j.tripleo.2011.04.006.

89. Chen J, et al. Hexokinase 2 overexpression promotes the proliferation and survival of laryngeal squamous cell carcinoma. Tumor Biology. 2014; 35(4):3743-3753. https://doi.org/10.1007/ s13277-013-1496-2. [PubMed: 24363061]

90. Miao P, et al. Lactate Dehydrogenase A in Cancer: A Promising Target for Diagnosis and Therapy. Iubmb Life. 2013; 65(11):904-910. https://doi.org/10.1002/iub.1216. [PubMed: 24265197]

91. Shi M, et al. A novel KLF4/LDHA signaling pathway regulates aerobic glycolysis in and progression of pancreatic cancer. Clin Cancer Res. 2014; 20(16):4370-80. https://doi.org/ 10.1158/1078-0432.CCR-14-0186. [PubMed: 24947925]

92. Fantin VR, St-Pierre J, Leder P. Attenuation of LDH-A expression uncovers a link between glycolysis, mitochondrial physiology, and tumor maintenance (vol 9, pg 425, 2006). Cancer Cell. 2006; 10(2):172-172. https://doi.org/10.1016/j.ccr.2006.07.011.

93. Fantin VR, St-Pierre J, Leder P. Attenuation of LDH-A expression uncovers a link between glycolysis, mitochondrial physiology, and tumor maintenance. Cancer Cell. 2006; 9(6):425-434. https://doi.org/10.1016/j.ccr.2006.04.023. [PubMed: 16766262]

94. Blatt, S., et al. Lactate as a predictive marker for tumor recurrence in patients with head and neck squamous cell carcinoma (HNSCC) post radiation: a prospective study over 15 years; Clin Oral Investig. 2016. p. 8https://doi.org/10.1007/s00784-015-1699-6

95. Ganapathy-Kanniappan, S., Geschwind, JFH. Tumor glycolysis as a target for cancer therapy: progress and prospects; Molecular Cancer. 2013. p. 12https://doi.org/10.1186/1476-4598-12-152

96. Pinheiro C, et al. Role of monocarboxylate transporters in human cancers: state of the art. Journal of Bioenergetics and Biomembranes. 2012; 44(1):127-139. https://doi.org/10.1007/ s10863-012-9428-1. [PubMed: 22407107]

97. Halestrap AP. The monocarboxylate transporter family--Structure and functional characterization. IUBMB Life. 2012; 64(1):1-9. https://doi.org/10.1002/iub.573. [PubMed: 22131303]

98. Pinheiro, C., et al. Expression of Monocarboxylate Transporters 1, 2, and 4 in Human Tumours and Their Association with CD147 and CD44. Journal of Biomedicine and Biotechnology. 2010. https://doi.org/10.1155/2010/427694

99. Baek G, et al. MCT4 Defines a Glycolytic Subtype of Pancreatic Cancer with Poor Prognosis and Unique Metabolic Dependencies. Cell Reports. 2014; 9(6):2233-2249. https://doi.org/10.1016/ j.celrep.2014.11.025. [PubMed: 25497091]

100. Zhu J, et al. Monocarboxylate Transporter 4 Facilitates Cell Proliferation and Migration and Is Associated with Poor Prognosis in Oral Squamous Cell Carcinoma Patients. Plos One. 2014; 9(1) https://doi.org/10.1371/journal.pone.0087904.

101. Ullah MS, Davies AJ, Halestrap AP. The plasma membrane lactate transporter MCT4, but not MCT1, is up-regulated by hypoxia through a HIF-1 alpha-dependent mechanism. Journal of Biological Chemistry. 2006; 281(14):9030-9037. https://doi.org/10.1074/jbc.M511397200. [PubMed: 16452478]

102. Dimmer KS, et al. The low-affinity monocarboxylate transporter MCT4 is adapted to the export of lactate in highly glycolytic cells. Biochemical Journal. 2000; 350:219-227. https://doi.org/ 10.1042/0264-6021:3500219https://doi.org/10.1042/bj3500219. [PubMed: 10926847] 
103. Feron O. Pyruvate into lactate and back: From the Warburg effect to symbiotic energy fuel exchange in cancer cells. Radiotherapy and Oncology. 2009; 92(3):329-333. https://doi.org/ 10.1016/j.radonc.2009.06.025. [PubMed: 19604589]

104. Grillon E, et al. The spatial organization of proton and lactate transport in a rat brain tumor. PLoS One. 2011; 6(2):e17416. https://doi.org/10.1371/journal.pone.0017416. [PubMed: 21390324]

105. Bonuccelli G, et al. Ketones and lactate "fuel" tumor growth and metastasis Evidence that epithelial cancer cells use oxidative mitochondrial metabolism. Cell Cycle. 2010; 9(17):35063514. https://doi.org/10.4161/cc.9.17.12731. [PubMed: 20818174]

106. Whitaker-Menezes D, et al. Evidence for a stromal-epithelial "lactate shuttle" in human tumors MCT4 is a marker of oxidative stress in cancer-associated fibroblasts. Cell Cycle. 2011; 10(11): 1772-1783. https://doi.org/10.4161/cc.10.11.15659. [PubMed: 21558814]

107. Boidot R, et al. Regulation of monocarboxylate transporter MCT1 expression by p53 mediates inward and outward lactate fluxes in tumors. Cancer Res. 2012; 72(4):939-48. https://doi.org/ 10.1158/0008-5472.CAN-11-2474. [PubMed: 22184616]

108. Colen CB, et al. Metabolic targeting of lactate efflux by malignant glioma inhibits invasiveness and induces necrosis: an in vivo study. Neoplasia. 2011; 13(7):620-32. https://doi.org/10.1593/ neo.11134. [PubMed: 21750656]

109. Curry JM, et al. Tumor microenvironment in head and neck squamous cell carcinoma. Semin Oncol. 2014; 41(2):217-34. https://doi.org/10.1053/j.seminoncol.2014.03.003. [PubMed: 24787294]

110. Maschek G, et al. 2-deoxy-D-glucose increases the efficacy of adriamycin and paclitaxel in human osteosarcoma and non-small cell lung cancers in vivo. Cancer Res. 2004; 64(1):31-4. https://doi.org/10.1158/0008-5472.CAN-03-3294. [PubMed: 14729604]

111. Simons AL, et al. 2-Deoxy-D-glucose combined with cisplatin enhances cytotoxicity via metabolic oxidative stress in human head and neck cancer cells. Cancer Res. 2007; 67(7):336470. https://doi.org/10.1158/0008-5472.CAN-06-3717. [PubMed: 17409446]

112. Simons AL, et al. Enhanced response of human head and neck cancer xenograft tumors to cisplatin combined with 2-deoxy-D-glucose correlates with increased (18)f-fdg uptake as determined by pet imaging. International Journal of Radiation Oncology Biology Physics. 2007; 69(4):1222-1230. https://doi.org/10.1016/j.ijrobp.2007.07.2343.

113. Rosbe KW, et al. Effect of lonidamine on the cytotoxicity of four alkylating agents in vitro. Cancer Chemother Pharmacol. 1989; 25(1):32-6. https://doi.org/10.1007/BF00694335. [PubMed: 2590999]

114. Mohanti BK, et al. Improving cancer radiotherapy with 2-deoxy-D-glucose: phase I/II clinical trials on human cerebral gliomas. Int J Radiat Oncol Biol Phys. 1996; 35(1):103-11. https:// doi.org/10.1016/S0360-3016(96)85017-6. [PubMed: 8641905]

115. Simons AL, et al. Glucose deprivation-induced metabolic oxidative stress and cancer therapy. J Cancer Res Ther. 2009; 5(Suppl 1):S2-6. https://doi.org/10.4103/0973-1482.55133. [PubMed: 20009288]

116. Landau BR, Lubs HA. Animal responses to 2-deoxy-D-glucose administration. Proc Soc Exp Biol Med. 1958; 99(1):124-7. https://doi.org/10.3181/00379727-99-24268. [PubMed: 13601788]

117. Dwarkanath BS, et al. Heterogeneity in 2-deoxy-D-glucose-induced modifications in energetics and radiation responses of human tumor cell lines. Int J Radiat Oncol Biol Phys. 2001; 50(4): 1051-61. https://doi.org/10.1016/S0360-3016(01)01534-6. [PubMed: 11429233]

118. Aykin-Burns N, et al. Increased levels of superoxide and $\mathrm{H} 2 \mathrm{O} 2$ mediate the differential susceptibility of cancer cells versus normal cells to glucose deprivation. Biochem J. 2009; 418(1):29-37. https://doi.org/10.1042/BJ20081258. [PubMed: 18937644]

119. Ihrlund LS, et al. 3-Bromopyruvate as inhibitor of tumour cell energy metabolism and chemopotentiator of platinum drugs. Molecular Oncology. 2008; 2(1):94-101. https://doi.org/ 10.1016/j.molonc.2008.01.003. [PubMed: 19383331]

120. Colella E, et al. Randomised phase II study of methotrexate (MTX) versus methotrexate plus lonidamine (MTX + LND) in recurrent and/or metastatic carcinoma of the head and neck. Eur J Cancer. 1994; 30A(7):928-30. https://doi.org/10.1016/0959-8049(94)90116-3. [PubMed: 7946585] 
121. Magno L, et al. Double-Blind Randomized Study of Lonidamine and Radiotherapy in Head and Neck-Cancer. International Journal of Radiation Oncology Biology Physics. 1994; 29(1):45-55. https://doi.org/10.1016/0360-3016(94)90225-9.

122. Wang YD, Li SJ, Liao JX. Inhibition of glucose transporter 1 (GLUT1) chemosensitized head and neck cancer cells to cisplatin. Technol Cancer Res Treat. 2013; 12(6):525-35. https://doi.org/ 10.7785/tcrt.2012.500343. [PubMed: 23617290]

123. Li S, et al. The effects of GLUT1 on the survival of head and neck squamous cell carcinoma. Cell Physiol Biochem. 2013; 32(3):624-34. https://doi.org/10.1159/000354466. [PubMed: 24022001] 


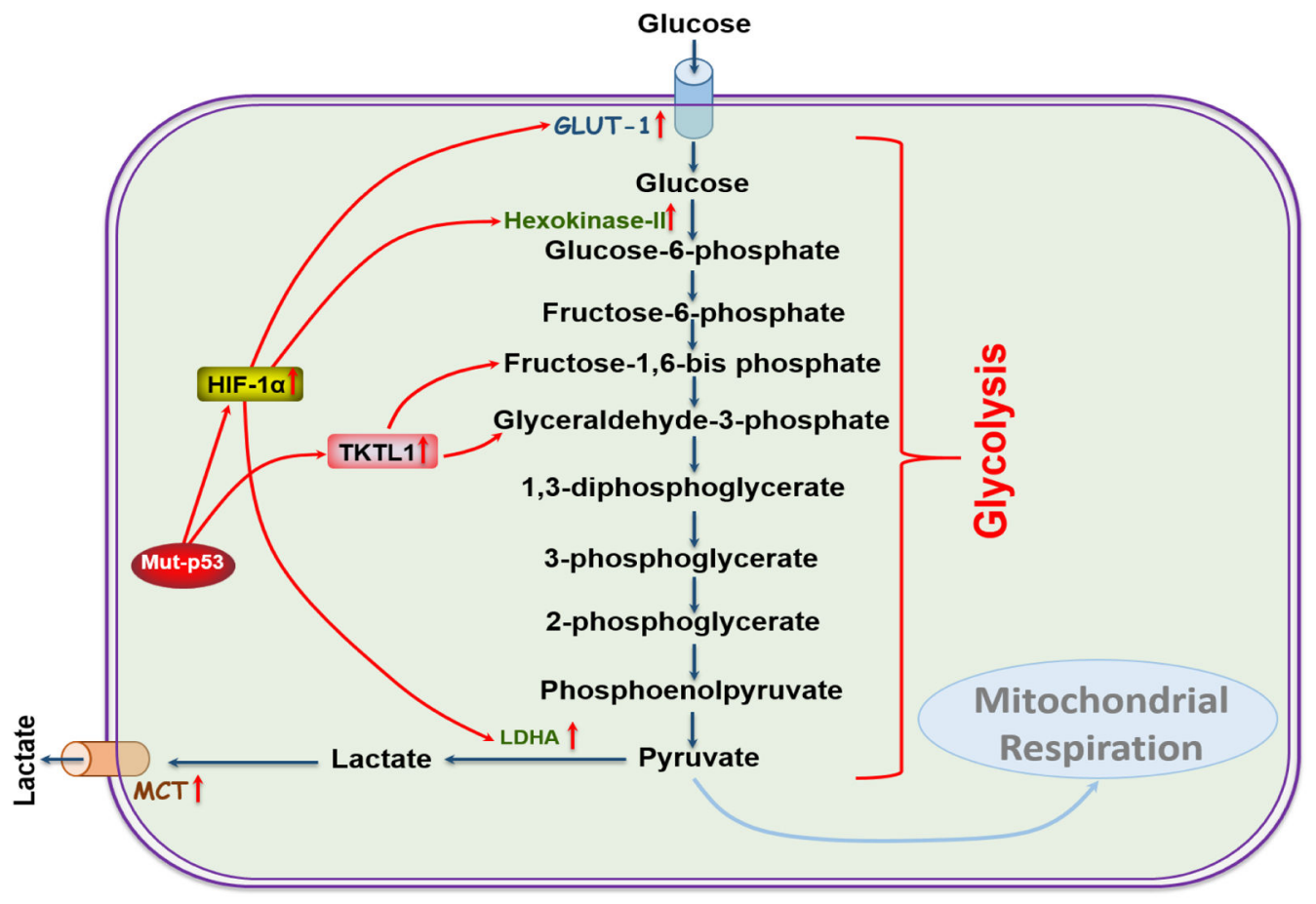

Figure 1. Regulation of HNSCC glycolysis

HNSCC tumors are more dependent on glycolysis. This model represents the regulation of glycolysis in HNSCC. Mutation in p53 activates HIF-1a, which regulates GLUT-1, HK-II and LDH-A expression in HNSCC. The overexpression of TKTL1 in HNSCC increases lactate production by increasing fructose-6-phosphate and glyceraldehyde-3-phosphate activity. Overexpression of MCTs export lactate out from the cells to protect cell damage as of the high accumulation of lactate decreases $\mathrm{pH}$ in intracellular environment. 